\title{
CORRIGENDUM
}

\section{A20 is targeted by promoter methylation, deletion and inactivating mutation in MALT lymphoma}

E Chanudet, Y Huang, K Ichimura, G Dong, RA Hamoudi, J Radford, AC Wotherspoon, PG Isaacson, J Ferry and M-Q Du

Leukemia (2010) 24, 488-489; doi:10.1038/leu.2009.278

Correction to: Leukemia (2010) 24, 483-487; doi:10.1038/ leukemia.2009.234; published online 12 November 2009
Since the publication of this paper, the authors have noticed an error in Table 1. The correct version is shown here. 


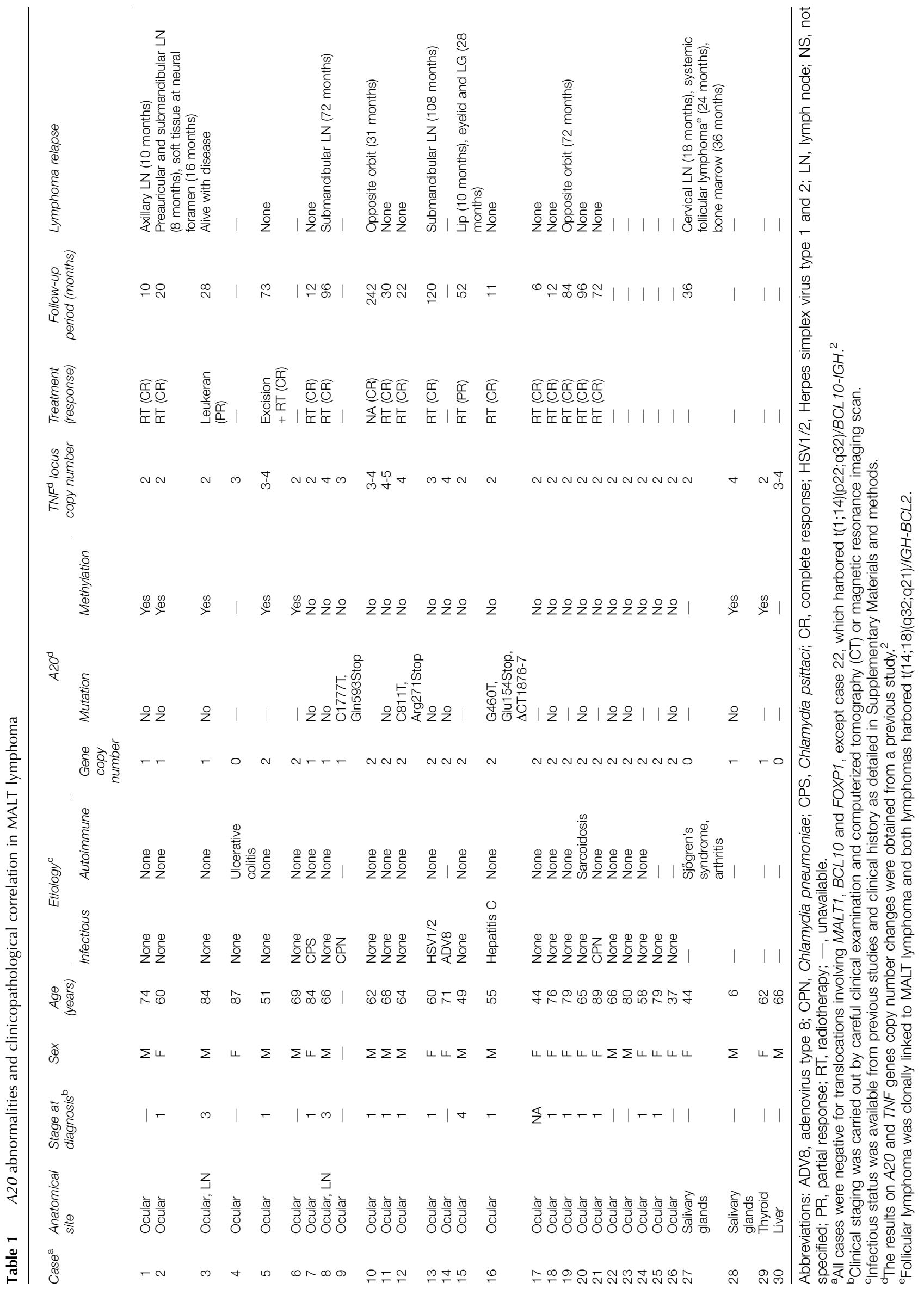

